\title{
Analisis Value chain Dalam Desain Alert System Pengajuan Jabatan Fungsional Dosen
}

\author{
Citra Wiguna $^{1 *}$, Afandi Nur Aziz Thohari ${ }^{2}$ \\ ${ }^{1}$ Jurusan Sistem Informasi, Fakultas Teknologi Industri dan Informatika, Institut Teknologi Telkom Purwokerto \\ ${ }^{2}$ Jurusan Rekayasa Perangkat Lunak, Fakultas Teknologi Industri dan Informatika, Institut Teknologi Telkom Purwokerto \\ 1,2 Jl. D. I. Panjaitan No. 128, 53147, Indonesia, \\ email: ${ }^{1}$ citra@ittelkom-pwt.ac.id, ${ }^{2}$ afandi@ittelkom-pwt.ac.id
}

Copyright @2019, Politeknik Harapan Bersama, Tegal

\begin{abstract}
Information and communication technology (ICT) currently become one of the important things to increasing excellence in various fields, where one of field is education. Institut Teknologi Telkom Purwokerto (ITTP) is an educational institution that has a focus on ICT technology development.One of the ICT development conducted by ITTP is the existence of an alert system for submitting functional lecturer position. This alert system can produce competent lecturer and can pass the qualifications according to the rules set. In the construction of alert system, absolutely must be through desain, and corresponding with requirement and business process that exist in ITTP. Therefore in this study was conducted alert system design analysis for the submission of functional lecturer position. The analytical method that used is a Value chain which has been proven to increase the strategic step of the product. The result of this research is strength weakness analysis in the alert system design that useful for institution and also lecturer in order to improve the quality and level that is controlled and directed.
\end{abstract}

\begin{abstract}
Abstrak - Teknologi informasi dan komunikasi (TIK) saat ini menjadi salah satu hal penting dalam meningkatkan keunggulan kompetitif diberbagai bidang, dimana salah satunya adalah bidang pendidikan. Institut Teknologi Telkom Purwokerto (ITTP) adalah institusi pendidikan yang memiliki fokus pada pengembangan teknologi TIK. Salah satu pengembangan TIK yang dilakukan ITTP adalah adanya sebuah alert system untuk pengajuan jabatan fungsional dosen. Adanya alert system ini dapat melahirkan dosen yang kompeten dan dapat memenuhi kualifikasi berdasarkan aturan yang ditetapkan. Dalam pembuatan alert system tentunya harus melalui desain, serta sesuai dengan kebutuhan dan proses bisnis yang ada di ITTP. Oleh karena itu pada penelitian ini dilakukan analisis desain alert system untuk pengajuan jabatan fungsional dosen. Metode analisis yang digunakan adalah Value chain yang sudah terbukti dapat meningkatkan langkah stategik dari produk. Hasil dari penelitian ini berupa analisis strength weakness dalam desain alert system yang bermanfaat bagi institusi maupun dosen dalam rangka peningkatan kualitas dan mutu yang terkontrol dan tearah.
\end{abstract}

Kata Kunci - alert system, dosen, ITTP, Value chain

*) Corresponding author: (Citra Wiguna)

Email: citra@ittelkom-pwt.ac.id

\section{PENDAHULUAN}

Teknologi informasi dan komunikasi (TIK) saat ini menjadi salah satu hal penting dalam meningkatkan keunggulan kompetitif diberbagai bidang. Tidak hanya di bidang industri saja, peran TIK dalam bidang pendidikan pun sangat diperhitungkan.

Institut Teknologi Telkom Purwokerto (ITTP) adalah institusi pendidikan tinggi yang memiliki fokus pada pengembangan teknologi ICT melalui penyelenggaraan berbagai program studi yang relevan, terletak di Jawa Tengah, Indonesia. ITTP merupakan lembaga pendidikan tinggi di bawah naungan Yayasan Pendidikan Telkom (YPT) yang memiliki komitmen untuk senantiasa menjalin hubungan yang harmonis dengan masyarakat dan lingkungan di wilayah ITTP berada. ITTP memiliki 8 program studi, yaitu D3 Teknik Telekomunikasi, S1 Teknik Telekomunikasi, S1 Informatika, S1 Sistem Informasi, S1 Rekayasa Perangkat Lunak, S1 Teknik Elektro, S1 Desain Komunikasi Visual, dan S1 Teknik Industri [1].

Peranan setiap Program Studi dituntut untuk menjawab segala tantangan serta kebutuhan masyarakat dengan peningkatan kualitas dosen dan kemajuan teknologi. Menjawab keraguan masyarakat akan program studi baru di Institut Teknologi Telkom Purwokerto, setiap program studi harus memiliki dosen yang berkompeten dan memenuhi kualifikasi sesuai dengan aturan dari pemerintah.

Kualifikasi dosen mengenai kenaikan jabatan fungsional dosen dapat dilihat berdasarkan angka kredit, setiap jenjang memiliki angka kredit (kum) yang berbeda-beda. Angka kredit untuk kenaikan pangkat/jabatan dihitung sejak jabatan/kenaikan nilai angka kredit terakhir berdasarkan penetapan/keputusan pejabat yang berwenang. Angka kredit seluruh kegiatan diperoleh dari pelaksanaan pendidikan, pengajaran, pengabdian kepada masyarakat dan penunjang yang sifatnya absolut. Sedangkan penilaian kegiatan penelitian bersifat maksimun. Pemberian angka kredit sangat tergantung pada mutu, sofistikasi dan kemuktahiran karya yang dinilai oleh rekan sejawat. Oleh karena itu diperlukan dukungan penuh dari unit Program studi maupun Fakultas untuk memenuhi syarat kenaikan karir dosen [2].

Sejalan dengan fokus institusi dengan pengembangan teknologi ICT, maka dalam mendukung pengajuan jabatan fungsional dosen dibutuhkan sebuah alert system. Sistem 
pengingat ini digunakan untuk mengingatkan kapan waktu yang tepat seorang dosen sudah dinyatakan sesuai dengan kualifikasi kenaikan karir dosen.

Agar pengembangan alert system dapat dilaksanakan dengan baik, diperlukan sebuah metode yang tepat. Dalam penelitian ini digunakan Value chain yang digunakan untuk menganalisis proses bisnis pengajuan jabatan fungsional dosen. Penerapan metode ini diharapkan mampu menciptakan nilai tambah untuk setiap proses bisnis di unit Program Studi maupun Fakultas. Selain itu, tujuan dilakukannya analisis Value chain adalah untuk mengidentifikasi tahap-tahap dimana institusi dapat mengambil langkah yang efektif dalam penerapan alert system pengajuan jabatan fungsional dosen.

Value chain merupakan konsep biaya disetiap aktivitas dan memahami sumber-sumber yang telah ada serta yang masih berpotensi dikembangkan dari masing-masing aktivitas dalam organissi perusahaan [3]. Value chain terdiri dari 2 aktivitas yaitu aktivitas utama dan aktivitas pendukung. Aktivitas utama merupakan bagian dari representasi dari arsitektur bisnis pada pengajuan jabatan fungsional dosen. Dalam aktivitas utama terbagi menjadi 4 tahap, berupa : persiapan, pelaksanaan, penilaian, dan pemeriksaan. Aktivitas pendukung terdapat 1 tahap, berupa : pelayanan administrasi.

Ruang lingkup penelitian dibatasi pada proses bisnis di unit Program Studi dan Fakultas. Proses analisa dilakukan menyeluruh sesuai dengan aktivitas pada metode Value chain yang telah ditetapkan. Perlunya akan alert system pengajuan jabatan fungsional dosen dalam lingkungan institusi diharapkan mampu meningkatkan kinerja unit Prodi dan dosen agar sesuai dengan aturan yang telah diterapkan. Alert system pengajuan jabatan fungsional dosen ini akan sangat bermanfaat bagi Institusi karena proses peningkatan kualitas dosen maupun Institusi lebih terkontrol dan tearah.

Berdasarkan permasalahan tersebut, maka pada penelitian dilakukan analisis desain alert system untuk jabatan fungsional dosen di Institut Teknologi Telkom Purwokerto. Metode yang digunakan untuk analisis adalah Value chain yang memang terbukti dapat memberikan penilaian untuk setiap proses bisnis yang berjalan.

\section{PENELITIAN YANG TERKAIT}

Alert system digunakan hampir pada berbagai bidang. Seperti contohnya pada bidang industri makanan, kemudian untuk memberitahukan kejadian yang sangat krusial seperti bencana alam, hingga pengingat dalam kehidupan sehari-hari Pada industri makanan telah dilakukan penelitian mengenai manajemen stok makanan dan minuman pada sebuah restoran. Penelitian tersebut dilakukan dengan metode RAD dalam pengembangan perancangan perangkat lunaknya. Sistem akan memberi peringatan bahwa stok makanan maupun minuman di restoran tersebut akan habis, dengan tujuan agar stok menu selalu tersedia untuk kebutuhan restoran tersebut [4].

Pembuatan sistem untuk bencana alam (banjir) pun dilakukan. Hasilnya berupa informasi yang didapatkan secara realtime untuk menampilkan data ketinggian air dan status banjir yang terdiri atas status kondisi aman, waspada dan bahaya [5]. Penelitian lain mengenai peringatan dini pada kebocoran gas dan asap menggunakan sensor gas MQ-7. Penelitian ini menggunakan metode fuzzy logic dalam mendeteksi kandungan gas yang ada di sebuah ruangan beserta indikator lampu hijau atau merah. Penelitian ini masih perlu pengembangan lanjutan seperti, simulasi keadaan ruangan yang memiliki gedung dengan lantai lebih dari satu [6].

Selain pentingnya sebuah alert system yang telah dijelaskan diatas, metode dalam rangka analisis kebutuhan sistem juga sangat diperlukan. Penelitian dengan metode Value chain dan CSF memberikan gambaran bahwa sistem informasi yang sesuai dengan faktor penentu kesuksesan sebuah perusahaan dan kemudahan perusahaan dalam menentukan langkah untuk membangun sebuah sistem yang menguntungkan bagi perusahaan[7].

Tidak hanya faktor internal saja yang dibutuhkan, analisis lingkungan internal dan eksternal dapat diterapkan dengan Value chain dan Force Factors Porter untuk hasil dari penelitian ini adalah perencanaan sistem informasi strategis di sebuah instansi[8].

Sejauh ini, peran Value chain dalam penerapan teknologi baru tampaknya masih kecil. Melihat dari laju pertumbuhan konsumsi dan produksi susu di India yang mulai mengadopsi teknologi untuk meningkatkan kehandalan teknologi didaerah tertentu[9]. Selain itu analisis Value chain juga dilakukan Burkina Faso dari mulai proses produksi hingga konsumsi. Aspek yang dinilai dalam penelitian ini yaitu sosial, ekonomi, lingkungan dan hukum. Studi ini menyediakan gambaran umum mengenai situasi di Cassou, sebuah desa kecil di Burkina Faso dan menyatakan perlunya fuelwood Value chain, tujuannya agar mampu menciptakan dan merumuskan strategi kebijakan[10].

Penerapan analisa konsep rantai nilai digunakan dalam menentukan sistem informasi yang ada pada PT Intan Pariwara, hasilnya berupa Strategi bisnis PT Intan Pariwara, seperti: strategi pengembangan pemasaran melalui internet dan strategi peningkatan hubungannya dengan pelanggan melalui sistem CRM. Penelitian ini menyarankan pengembangan sistem berupa situs interaktif dan sistem CRM [11]. Menurut Suhartini, dalam penelitiannya analisis Value chain digunakan sebagai alat analisis strategi untuk mengetahui keunggulan kompetitif, peningkatan nilai tambah (value added) dan penurunan biaya sehingga usaha batik lebih kompetitif [12].

Berbeda dengan penelitian value chain sebelumnya, penelitian ini hanya melingkupi analisis Value chain dalam desain alert system pengajuan jabatan fungsional dosen yang menghasilkan analisis strength weakness.

\section{VALUE CHAIN}

Rantai nilai (Value chain) merupakan serangkaian proses produktif mulai dari input sebuah produk hingga output ke konsumen akhir. Rantai nilai (Value chain) diperkenalkan oleh Michael Porter, yang merupakan sebuah acuan untuk menganalisa aktivitas-aktivitas spesifik yang dapat menciptakan nilai dan keunggulan kompetitif disetiap tahapan dalam organisasi.

Aktivitas dalam Value chain dibagi dalam 2 jenis, yaitu: Aktifitas utama (primary actvities) dan aktifitas pendukung (suppory activities). Langkah awal dalam penerapan Value chain adalah memetakan proses bisnis suatu perusahaan menjadi aktivitas utama atau aktivitas pendukung [13]. Ketika Value chain telah dipetakan, pengelola institusi harus mengidentifikasikan kepuasan bagi stakeholder. Gbr 1 menunjukkan konsep rantai nilai Porter. 


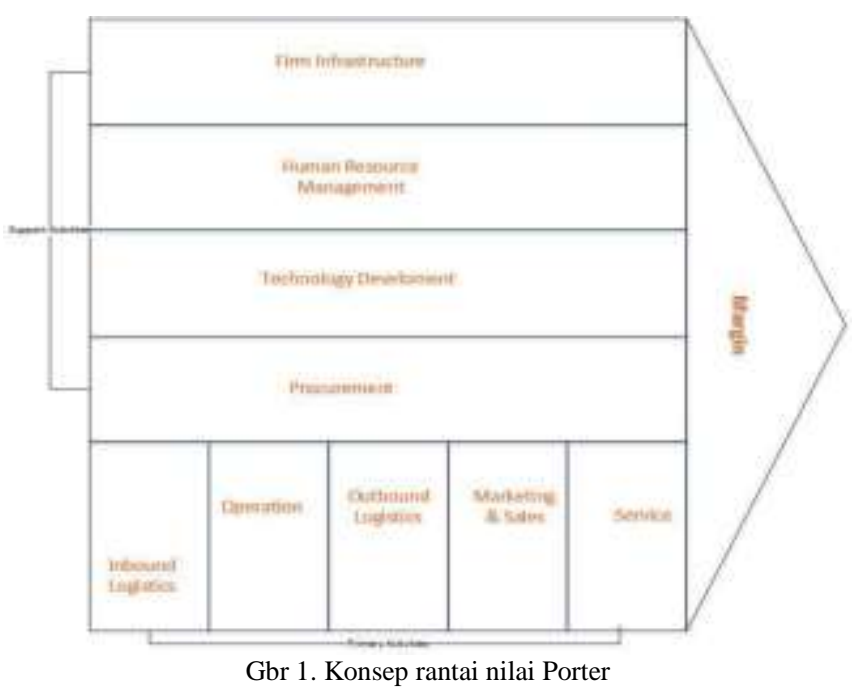

dosen yang sedang melakukan pengajukan jabatan fungsional yang berperan sebagai pakar yang memberikan informasi terkait proses pengajuan jabatan fungsional dosen.

Hasil wawancara yang telah dikumpulkan kemudian dimodelkan sesuai dengan kebutuhan unit. Hasilnya berupa analisa strength dan weakness dalam pengembangan desain alert system pengajuan jabatan fungsional dosen. Adapun prosedur penelitian di atas dapat ditunjukkan pada Gbr.2.

\section{HASIL DAN PEMBAHASAN}

Penelitian ini menggunakan metode wawancara yang dilakukan pada pihak SDM dan Dosen yang sedang melakukan pengajuan jabatan fungsioanl dosen di lingkungan ITTP. Wawancara yang dilakukan berdasarkan metode Value chain yang telah ditetapkan sebelumnya. Hasilnya berupa: hasil wawancara, hasil analisis dengan value chain, hasil analisis strength dan weakness desain alert system pengajuan jabatan fungsional dosen. Sebelum adanya wawancara, dilakukan pemetaan terhadap proses bisnis yang ada dengan metode Value chain. Proses bisnis dipetakan sesuai dengan Gbr. 3.

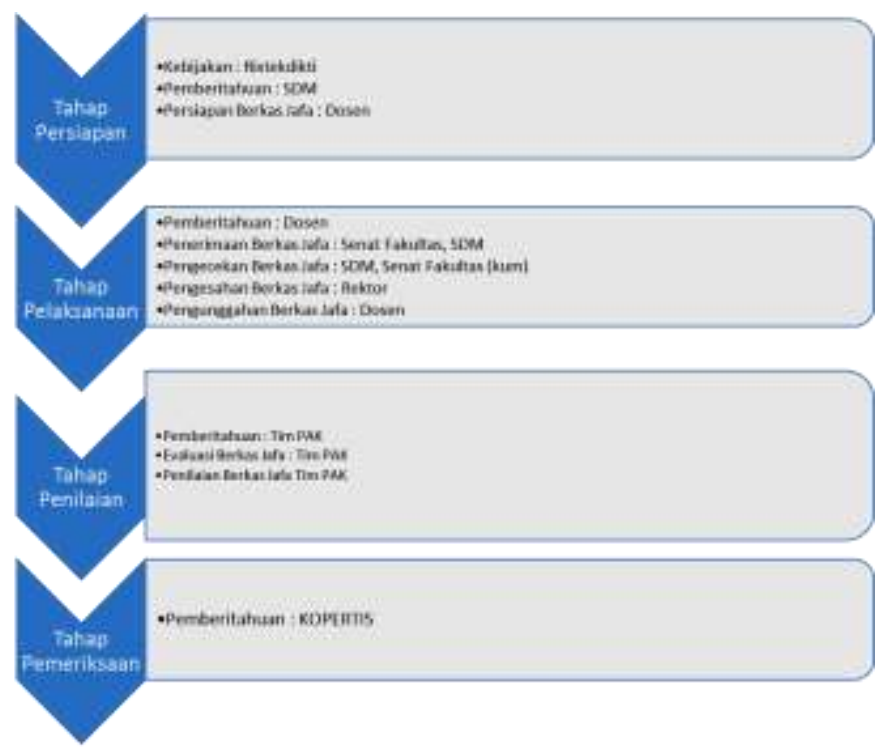

Gbr 3. Pemetaan Proses Bisnis

\section{Hasil Streagth Weakness Alert System} Peagajuan Jabatan Fungsional Dosen

Gbr 2. Prosedur Penelitian

\section{METODE PENELITIAN}

Prosedur penelitian dimulai dengan tahap identifikasi masalah penelitian yaitu dengan memahami proses bisnis yang berjalan. Tahap selanjutnya dilakukan kajian pustaka dengan melakukan pengumpulan data dengan cara wawancara. Setelah didapatkan data, kemudian dilakukan pemetaan hasil wawancara dan dianalisis dengan metode Value chain. Analisis dengan metode Value chain yang dibedakan menjadi 2 aktivitas, yaitu: aktivitas utama dan aktivitas pendukung. Beberapa unit terkait dengan aktivitas utama seperti: unit program studi, Dosen, Senat Fakultas dan Tim Penilai Angka Kredit (PAK). Pada tahap ini, wawancara dilakukan dengan pihak SDM selaku bagian dari Tim PAK institusi dan dengan

\section{A. Hasil Wawancara}

Tabel I menunjukkan indikator pertanyaan yang diajukan untuk menganalisis proses bisnis dalam pengajuan jabatan fungsional dosen. Proses pengajuan jabatan fungsional dosen disesuaikan dengan metode Value chain. Tahapan ini disusun berdasarkan prosedur penelitian Gbr 2. Tabel indikator pertanyaan ditunjukkan pada Tabel I.

\section{B. Hasil Analisis dengan Value chain}

Proses yang dilakukan dalam pencarian data dan informasi dalam penelitian ini menggunakan metode wawancara pada Poin 4.1 yang selanjutnya dipetakan kedalam value chain. Metode value chain mampu menganalisis kondisi saat ini dalam pengajuan jabatan fungsional dosen.

Unit yang terkait dengan pengajuan jabatan fungsioanl dosen yaitu: unit program studi dan Fakultas dan terbagi menjadi 2 aktivitas (utama dan pendukung) dan 4 tahap (persiapan, pelaksaan, penilaian dan pemeriksaan). Dalam 
tahap persiapan dilakukan analisis mengenai kebijakan dan perencanaan tahap awal dalam pengajuan jabatan fungsional dosen. Tahap pelaksaan terdapat proses penerimaan, pengecekan, pengesahan dan pengguhan berkas pengajuan jabatan fungsional dosen. Tahap penilaian terdapat proses evaluasi dan penilaian berkas pengajuan jabatan fungsional dosen. Tahap pemeriksaan terdapat proses pemberitahuan bahwa berkas pengajuan jabatan fungsional dosen diajukan ke KOPERTIS.

TABEL I

INDIKATOR PERTANYAAN

\begin{tabular}{|c|c|c|c|}
\hline Unit & Tohan & & Sub indilrator \\
\hline Dosen & Persiapan & $\begin{array}{l}\text { Kebijakan } \\
\text { Pemberitahuan } \\
\text { Persiapan } \\
\text { berkas }\end{array}$ & $\begin{array}{l}\text { Prosedur satuan } \\
\text { mutu, Ristekdikti } \\
\text { Pemberitahuan } \\
\text { eligible Jafa } \\
\text { Persiapan berkas } \\
\text { pendidikan, penelitian, } \\
\text { pengabdian, kepada } \\
\text { masyarakat dan } \\
\text { penunjang }\end{array}$ \\
\hline $\begin{array}{c}\text { Senat } \\
\text { Fakultas }\end{array}$ & Pelaksanaan & $\begin{array}{l}\text { Pemberitahuan } \\
\text { Penerimaan } \\
\text { berkas } \\
\text { Jafa } \\
\\
\text { Pengecekan } \\
\text { berkas } \\
\text { Jafa } \\
\\
\text { Pengesahan } \\
\text { berkas Jafa } \\
\text { Pengunggahan } \\
\text { berkas } \\
\text { Jafa }\end{array}$ & $\begin{array}{l}\text { Pemberitahuan } \\
\text { eligible Jafa } \\
\text { Penerimaan berkas } \\
\text { pendidikan, penelitian, } \\
\text { pengabdian, } \\
\text { kepada masyarakat dan } \\
\text { penunjang } \\
\text { Pengecekan berkas } \\
\text { pendidikan, penelitian, } \\
\text { pengabdian, } \\
\text { kepada masyarakat dan } \\
\text { penunjang } \\
\text { Pengecekan kum } \\
\text { (angka kredit) } \\
\text { Pengesahan berkas } \\
\text { pendidikan, penelitian, } \\
\text { pengabdian, } \\
\text { kepada masyarakat dan } \\
\text { penunjang } \\
\text { Pengunggahan } \\
\text { berkas ke SIJAGO }\end{array}$ \\
\hline $\begin{array}{l}\text { Tim } \\
\text { PAK }\end{array}$ & Penilaian & $\begin{array}{l}\text { Pemberitahuan } \\
\text { Evaluasi } \\
\text { berkas Jafa } \\
\text { Penilaian } \\
\text { berkas Jafa }\end{array}$ & $\begin{array}{l}\text { Pemberitahuan } \\
\text { revisi oleh Tim PAK }\end{array}$ \\
\hline & Pemeriksaan & Pemberitahuan & $\begin{array}{l}\text { Pemberitahuan } \\
\text { Revisi / diterima } \\
\text { oleh KOPERTIS }\end{array}$ \\
\hline
\end{tabular}

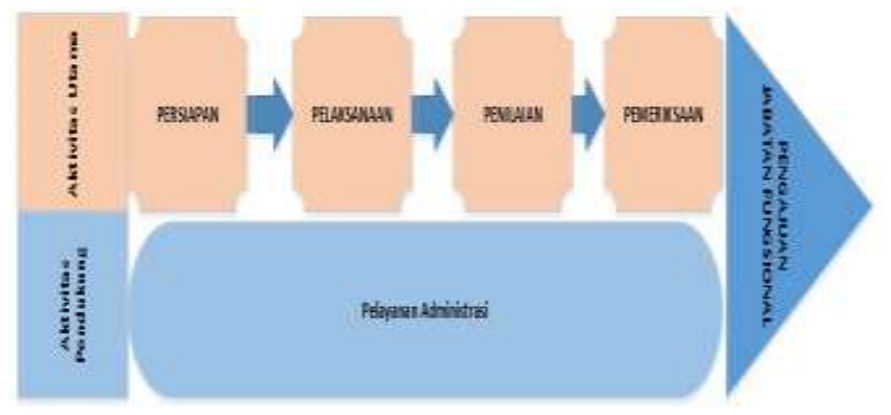

Gbr 4. Pelaksanaan aktivitas dengan value chain
Aktivitas lain dalam Value chain yaitu, aktifitas pendukung yang memberikan pelayanan administrasi pada setiap tahapan dalam Value chain (persiapan, pelaksanaan, penilaian dan pemeriksaan). Pelaksanaan aktivitas dengan Value chain ini ditunjukan pada Gbr 4.

\section{Hasil Analisis Strength Weakness}

Setelah melakukan pemetaan arsitektur proses bisnis jabatan fungsional dosen dengan wawancara dan metode value chain, diperoleh hasil berupa analisis Strength Weakness proses bisnis jabatan fungsional dosen yang ditunjukkan pada Tabel II.

TABEL II

HASIL ANALISIS STRENGTH WEAKNESS

\begin{tabular}{|c|c|}
\hline Strength & Weakness \\
\hline $\begin{array}{l}\text { Telah memiliki kebijakan yang } \\
\text { mengatur pengajuan jabatan } \\
\text { fungsional dosen }\end{array}$ & $\begin{array}{l}\text { Belum adanya } r \text { sistem } \\
\text { informasi pengajuan jabatan } \\
\text { fungsional dosen secara } \\
\text { internal (menggunakan } \\
\text { media sosial / tatap muka) }\end{array}$ \\
\hline $\begin{array}{l}\text { Dosen yang dimiliki oleh ITTP } \\
\text { saat ini sebagian besar berusia } \\
\text { muda }\end{array}$ & $\begin{array}{l}\text { Dosen yang memiliki jabatan } \\
\text { fungsional masih sangat } \\
\text { sedikit }(20 \%)\end{array}$ \\
\hline $\begin{array}{l}\text { Adanya kewajiban BKD untuk } \\
\text { setiap dosen setiap semester }\end{array}$ & Belum adanya guru besar \\
\hline $\begin{array}{l}\text { Pemenuhan jabfung dosen } \\
\text { dijadikan sebagai salah satu } \\
\text { kriteria ketercapaian dalam } \\
\text { Kontrak Manajemen (KM) }\end{array}$ & $\begin{array}{l}\text { Dosen dengan sertifikasi } \\
\text { masih terbatas jumlahnya }\end{array}$ \\
\hline $\begin{array}{l}\text { Adanya sosialisasi jabfung dari } \\
\text { fakultas }\end{array}$ & $\begin{array}{l}\text { Produktivitas dan digitalisasi } \\
\text { karya ilmiah masih rendah }\end{array}$ \\
\hline \multirow[t]{2}{*}{$\begin{array}{l}\text { Monitoring dan evaluasi } \\
\text { dilakukan secara periodik dari } \\
\text { atasan langsung kepada para } \\
\text { dosen }\end{array}$} & $\begin{array}{l}\text { Adanya ketidakseragaman } \\
\text { persepsi antar tim PAK }\end{array}$ \\
\hline & $\begin{array}{l}\text { Kurangnya tingkat kerapihan } \\
\text { dan ketelitian dalam } \\
\text { pendokumentasian ajuan } \\
\text { jabfung oleh setiap dosen }\end{array}$ \\
\hline
\end{tabular}

\section{KESIMPULAN}

Berdasarkan hasil analisis dan pembahasan, kesimpulan yang dapat diambil dalam penelitian ini yaitu metode Value chain dapat memberikan hasil strength dan weakness pada proses pengajuan jabatan fungsional dosen. Hasil strength dan weakness dapat dijadikan acuan sebagai pengambilan keputusan dalam pengajuan jabatan fungsional dosen dan menerapkan metode McFarlan untuk menganalisis kondisi teknologi informasi / sistem informasi (SI/TI) institusi, setelah dilakukan analisis strength weakness

Penelitian selanjutnya, dapat dilakukan analisis kelayakan desain pengajuan jabatan fungsional dosen dengan metode JAD (Joint Application Development) /wawancara langsung dengan user untuk mendapatkan requirement yang sesuai. Dapat dilakukan pula analisis strategi dengan CSF (Critical Success Factor) sesuai dengan hasil strength weakness agar pihak institusi mengetahui strategi yang paling sesuai dengan proses pengajuan jabatan fungsional dosen. 


\section{DAFTAR PUSTAKA}

[1] I. T. Telkom, Rencana strategis. 2018.

[2] T. dan P. T. Kementrian Riset, PERATURAN \&TATA CARA PENGAJUAN KENAIKAN JABATAN FUNGSIONAL DAN PANGKAT SECARA ON LINE. 2016.

[3] G. Rifai, Prinsip-prinsip pengelolaan strategi bisnis. PT Gramedia Pustaka Utama, 2012.

[4] B. Budiarto, N. Opier, A. D. Saputro, A. H. Mujianto, A. Sahala, and J. Prayitno, "PERANCANGAN SISTEM INFORMASI MANAJEMEN STOK MAKANAN," pp. 6-7, 2016.

[5] D. Satria, S. Yana, R. Munadi, and S. Syahreza, "Sistem Peringatan Dini Banjir Secara Real-Time Berbasis Web Menggunakan Arduino dan Ethernet," vol. 1, no. 1, pp. 1-6, 2017.

[6] A. Burhanuddin, "Aplikasi Sistem Peringatan Dini pada Kebocoran Gas dan Asap Menggunakan Sensor Gas MQ-7 dengan Program C," vol. 2, 2016

[7] M. H. Prayitno, P. Studi, and S. Informasi, “Analisa Kebutuhan Sistem Informasi Dengan Menggunakan Analisis Value Change Dan Critical Success Factor Pada PT . LHE,” vol. 3, no. 1, pp. 269-278, 2016.
[8] E. A. Kusuma and F. Force, "PERENCANAAN STRATEGIS SISTEM INFORMASI PT . ANUGERAH AULIA KALIMANTAN SELATAN,"pp. 9-14.

[9] E. Janssen and J. Swinnen, "Technology adoption and value chains in developing countries : Evidence from dairy in India," Food Policy, no. March 2016, pp. 0-1, 2017.

[10] Y. Puentes-rodriguez, P. Torssonen, S. Ramcilovik-suominen, and S. Pitkänen, "Fuelwood value chain analysis in Cassou and Ouagadougou , Burkina Faso: From production to consumption," Energy Sustain. Dev., vol. 41, pp. 14-23, 2017.

[11] N. D. Retnowati, "Penerapan Sistem Informasi Menggunakan Analisis Value Chain Studi Kasus : PT Intan Pariwara Klaten," pp. 73-80.

[12] E. Yuliawati, "ANALISIS VALUE CHAIN UNTUK PENINGKATAN DAYA SAING," no. 1, pp. 1-8, 2014.

[13] R. B. R. John A. Pearce, Strategic Management: Formulation, Implementation, and Control, 11, berilu ed. McGraw-Hill Higher Education, 2009, 2009. 